\title{
Treatment of Hepatitis C Virus Infection in Kidney Transplant Recipients: Case Report
}

\author{
F. Caeiro, V. Baptista, N. Rodrigues, D. Carvalho, I. Aires, F. Remédio, and F. Nolasco
}

\begin{abstract}
Chronic hepatitis $\mathrm{C}$ virus (HCV) infection exists in a large proportion of patients undergoing renal transplantation. Nowadays it is not considered to be an absolute contraindication to transplantation; however, it is associated with an increased risk for the patient and accounts for a shorter half-life of the renal allograft. We present three transplant recipients who displayed serious hepatic dysfunction after renal transplantation due to an HCV infection. In two of these cases, the liver biopsies established the diagnosis of FCH. In the third case, the liver biopsy was compatible with the early stages of FCH. All patients were started on peg-interferon alfa 2-b and ribavirin with subsequent normalization of hepatic function and early complete viral responses.
\end{abstract}

$\mathbf{H}$ EPATITIS C VIRUS (HCV) infection has a prevalence of $5 \%$ among hemodialysis (HD) patients in Portugal. ${ }^{1}$ Renal transplantation remains the best therapeutic option for chronic renal failure $(\mathrm{CRF})^{2}$ despite the fact that these patients show worse long-term outcomes due to infectious complications and hepatic failure. $^{3,4}$ Allograft half-life is also reduced due to chronic nephropathy, de novo membranoproliferative glomerulonephritis, membranous glomerulonephritis, cryoglobulinemia, and an increased risk of development of diabetes mellitus. ${ }^{5}$

HCV therapy is seldom used in transplanted patients, since a cure is only attained in $0 \%$ to $50 \%$ of cases; furthermore, few individuals achieve the end of the treatment due to the adverse effects $(0 \%-100 \%) .{ }^{6}$ Treatment is also associated with an increased risk of acute cellular and vascular rejection $(15 \%-60 \%)$, causing allograft loss in about $20 \%$ of cases, and rebound of viral load to pretreatment levels after its discontinuation. ${ }^{6}$ A rejection episode during HCV therapy is usually therapy-resistant and irreversible. $^{6}$

In fact, the only widely accepted indication for $\mathrm{HCV}$ treatment after transplantation is the development of fibrosing cholestatic hepatitis (FCH). ${ }^{7}$ Initially described in 1991 as a complication of a hepatitis B infection (HBV) in liver transplant recipient, ${ }^{8}$ this rare entity appears to be associated with HCV infection in renal transplantation. ${ }^{9}$ It seems to be associated with rapid viral replication in the immediate period following transplantation with the development of rapidly progressive hepatic failure with ensuing death. Herein we have presented three cases of renal transplant patients who developed $\mathrm{FCH}$ and underwent treatment for $\mathrm{HCV}$ infection.

\section{CASE REPORTS \\ Case 1}

A 59-year-old male Caucasian patient with CRF of unknown origin under HD for 68 months, had arterial hypertension and was HCV (genotype 2) positive since 2002. He was admitted for deceased donor renal transplantation in October 2007. His panel-reactive antibody (PRA) content was $98 \%$ and showed one HLA compatibility with the donor. Immunosuppression was performed with antithymocyte globulin, human immunoglobulin, tacrolimus (FK), mycophenolate mofetil (MMF) and corticosteroids (CT). In the immediate period following transplantation, he experienced an acute humoral rejection episode, which was treated with four courses of immunoglobulin and two of rituximab. At the time of discharge, he displayed good allograft function with serum creatinine of $1.2 \mathrm{mg} / \mathrm{dL}$, but he had developed diabetes mellitus. He did not receive any other blood derivatives besides immunoglobulin. His maintenance therapy was FK, MMF, and CT.

During the pretransplant period, he had undergone a normal abdominal ultrasound and displayed serum levels of alanine aminotransferase (ALT): $52 \mathrm{U} / \mathrm{L}$; aspartate aminotransferase (AST): $42 \mathrm{U} / \mathrm{L}$ : alkaline phosphatase (ALP): $173 \mathrm{U} / \mathrm{L}$; gamma-glutamyltransferase (G-GT): $260 \mathrm{U} / \mathrm{L}$; bilirubin: $0.6 \mathrm{mg} / \mathrm{dL}$; total protein: $7.1 \mathrm{~g} / \mathrm{dL}$; and albumin: $4.3 \mathrm{~g} / \mathrm{dL}$. Two months after transplantation, we noticed

From the Department of Nephrology, Hospital Curry Cabral, Lisboa, Portugal.

Address reprint requests to Fernando Caeiro, Serviço de Nefrologia, Rua da Beneficência No. 8 1069-166, Lisboa, Portugal. E-mail: fccaeiro@gmail.com

0041-1345/-see front matter doi:10.1016/j.transproceed.2011.01.001 
progressive hepatic dysfunction with AST: $143 \mathrm{U} / \mathrm{L}$; ALT: $120 \mathrm{U} / \mathrm{L}$; ALP: $173 \mathrm{U} / \mathrm{L}$; G-GT: $260 \mathrm{U} / \mathrm{L}$; and bilirubin: $3.2 \mathrm{mg} / \mathrm{dL}$. Serologies for cytomegalovirus (CMV) and HBV were negative. A hepatic biopsy showed a mixed infiltration of the portal area, hepatic baloonization, and hepatocanalicular cholestasis without fibrosis, suggesting iatrogenic hepatotoxicity.

We altered the immunosuppression to sirolimus, low-dose FK, and CT; however, progressive hepatic failure continued. At 3 months after transplantation he had AST: $168 \mathrm{U} / \mathrm{L}$; ALT: $122 \mathrm{U} / \mathrm{L}$; ALP: $144 \mathrm{U} / \mathrm{L}$; G-GT: $101 \mathrm{U} / \mathrm{L}$, and bilirubin: $20 \mathrm{mg} / \mathrm{dL}$. RNA HCV viral load was $7.6 \times 10^{6} \mathrm{U} / \mathrm{L}$. We repeated the hepatic biopsy, which now showed a mixed inflammatory infiltrate, ductal proliferation, and marked cholestasis of the parenchyma and canaliculus with moderated portal and pericellular fibrosis, aspects characteristic of FCH. He was started on peg-interferon alfa 2-b (PEG IFN $\alpha$-2b; 50 $\mu \mathrm{g} / \mathrm{wk})$ and ribavirin $(600 \mathrm{mg} / \mathrm{d})$ for 24 weeks. There was a marked improvement of hepatic function with AST: $47 \mathrm{U} / \mathrm{L}$; ALT: $28 \mathrm{U} / \mathrm{L}$; ALP: $191 \mathrm{U} / \mathrm{L}$; G-GT: $36 \mathrm{U} / \mathrm{L}$; and bilirubin: $1.1 \mathrm{mg} / \mathrm{dL}$. Allograft function was steady with a serum creatinine of $1.2 \mathrm{mg} / \mathrm{dL}$. There was a complete viral response with an RNA HCV: $<615 \mathrm{U} / \mathrm{L}$. One month after completion of therapy, a new biopsy revealed HCV chronic hepatitis with an activity level of $3 / 18$ by the modified histologic activity index and $5 / 6$ for fibrosis.

One month after finishing HCV therapy, he experienced a bout of acute humoral rejection with treatment with immunoglobulin. In April 2010, at 22 months after finishing therapy, he displayed: AST: 75 U/L; ALT: 38 U/L; ALP: 212 U/L; G-GT: 98 U/L; bilirubin: 0.9 $\mathrm{mg} / \mathrm{dL}$ and serum creatinine: $1.4 \mathrm{mg} / \mathrm{dL}$. Despite this satisfactory profile, a viral relapse was discovered 2 months after finishing therapy. His hemoglobin was stable during the full course of therapy and there was no need for the introduction of erythropoiesis-stimulating agents (ESA).

\section{Case 2}

A 40-year-old male Caucasian patient with CRF of unknown etiology underwent renal substitution therapy for 86 months (6 in $\mathrm{HD}$ and the remaining in peritoneal dialysis). A living donor renal transplant was performed in September 2009. He presented a PRA of $0 \%$ with one HLA match with the donor. He was started on thymoglobulin, FK, MMF, and CT. The early posttransplant period was uneventful and he was discharged with a serum creatinine of $1.5 \mathrm{mg} / \mathrm{dL}$. He did not receive any blood derivative transfusion. In the pretransplant period, he displayed normal hepatic function with consistently normal hepatic ultrasounds and negative serologies for $\mathrm{HCV}$ and $\mathrm{HBV}$. His maintenance therapy was FK, MMF, and CT.

One month after transplantation we noticed alterations in hepatic function AST: $143 \mathrm{U} / \mathrm{L}$; ALT: $208 \mathrm{U} / \mathrm{L}$; ALP: $826 \mathrm{U} / \mathrm{L}$; G-GT: $92 \mathrm{U} / \mathrm{L}$; and bilirubin: $1.5 \mathrm{mg} / \mathrm{dL}$. At that time, he was negative for $\mathrm{HBV}, \mathrm{HCV}$, and CMV, but the herpes virus 6 serology was a weak positive He received intravenous acyclovir without improvement. Two months after transplantation, the hepatic function worsened, with AST: $750 \mathrm{U} / \mathrm{L}$; ALT: $1116 \mathrm{U} / \mathrm{L}$; ALP: $280 \mathrm{U} / \mathrm{L}$; G-GT: 1126 $\mathrm{U} / \mathrm{L}$; and bilirubin: $6.4 \mathrm{mg} / \mathrm{dL}$. The first hepatic biopsy revealed a mixed inflammatory infiltrate with some eosinophils and focal hepatocellular necrosis without fibrosis. With the suspicion of iatrogenic hepatitis, immunosuppression was switched to sirolimus and prednisolone. However, there was no improvement in hepatic function. Polymerase chain reaction (PCR) for HCV showed RNA $\mathrm{HCV}>7.6 \times 10^{6} \mathrm{U} / \mathrm{L}$, genotype $3 \mathrm{a}$. A new hepatic biopsy showed mixed portal infiltration with ductal proliferation and cholestasis associated with pericellular fibrosis leading to the diagnosis of
FCH. We initiated therapy with PEG IFN $\alpha-2 b(50 \mu \mathrm{g} / \mathrm{wk})$ and ribavirin $(600 \mathrm{mg} / \mathrm{g})$. After 24 weeks of therapy, the hepatic function was AST: $39 \mathrm{U} / \mathrm{L}$; ALT: $41 \mathrm{U} / \mathrm{L}$; ALP: $96 \mathrm{U} / \mathrm{L}$; G-GT: 24 U/L; bilirubin: $0.3 \mathrm{mg} / \mathrm{dL}$; and RNA $\mathrm{HCV}<615 \mathrm{U} / \mathrm{L}$. He maintains normal renal function with a serum creatinine of 1.1 $\mathrm{mg} / \mathrm{dL}$. HCV serologies remain negative with a viral response sustained at 2 months after finishing therapy. The donor tested negative for $\mathrm{HCV}$ infection by serologic and PCR methods. No ESA therapy was required.

\section{Case 3}

A 51-year-old female Caucasian patient with CRF from repetitive bouts of pyelonephritis was under HD treatment for 108 months. At deceased donor renal allograft transplantation in September 2009, she presented two HLA compatibilities with the donor and a PRA of $12 \%$. Induction immunosuppression was performed with basiliximab, FK, MMF, and CT. She experienced late allograft function after HD dependence for 4 months due to extensive acute tubular necrosis and atheroembolism diagnosed by allograft biopsy. She also experienced an episode of acute humoral rejection, which was treated with immunoglobulin. During this period, she received $3 \mathrm{U}$ of erythrocyte concentrate. The maintenance immunosuppression was FK, MMF, and CT. Basal serum creatinine was $3.3 \mathrm{mg} / \mathrm{dL}$. HBV and HCV serologies, abdominal ultrasound, and hepatic function were normal before transplantation.

On a routine analysis about 3 months after transplantation we observed hepatic function AST: $142 \mathrm{U} / \mathrm{L}$; ALT: 197U/L; ALP: 177 U/L; G-GT: $137 \mathrm{U} / \mathrm{L}$; and bilirubin: $0.3 \mathrm{mg} / \mathrm{dL}$. Serologies for $\mathrm{HBV}, \mathrm{HCV}$, and CMV were negative. Over the 2 following months, there was progressive hepatic dysfunction. A liver biopsy showed a mixed sinusoidal infiltrate with mild cholestasis of the parenchyma as well as hepatocellular necrosis with some portal fibrosis. The diagnosis of iatrogenic hepatitis was deemed to be the most probable, we switched the maintenance therapy to sirolimus and CT. Despite this change hepatic function continued to deteriorate. At 5 months after transplantation it was AST: $462 \mathrm{U} / \mathrm{L}$; ALT: 373 U/L; ALP: $569 \mathrm{U} / \mathrm{L}$; G-GT: $1901 \mathrm{U} / \mathrm{L}$; and bilirubin $1.5 \mathrm{mg} / \mathrm{dL}$. HCV PCR showed $>7.6 \times 10^{6} \mathrm{U} / \mathrm{L}$, genotype $3 \mathrm{a}$. She was started on PEG IFN $\alpha$-2b (50 $\mu \mathrm{g} / \mathrm{wk})$ and ribavirin $(600 \mathrm{mg} / \mathrm{d})$. Eight weeks after starting therapy, the dose of PEG IFN $\alpha$-2b was reduced to 30 $\mu \mathrm{g} / \mathrm{wk}$ with a slight elevation in serum creatinine $(3.7 \mathrm{mg} / \mathrm{dL})$. At that time, the viral load was already undetectable (RNA HCV < $615 \mathrm{U} / \mathrm{L})$. After 12 weeks of therapy, she displayed normal hepatic function with AST: $26 \mathrm{U} / \mathrm{L}$; ALT: $14 \mathrm{U} / \mathrm{L}$; ALP: $121 \mathrm{U} / \mathrm{L} ; \mathrm{G}-\mathrm{GT}: 37$ $\mathrm{U} / \mathrm{L}$; and bilirubin: $0.4 \mathrm{mg} / \mathrm{dL}$ with unchanged renal function at a serum creatinine of $3.5 \mathrm{mg} / \mathrm{dL}$. Therapy was discontinued at 14 weeks because of renal dysfunction (creatinine: $4 \mathrm{mg} / \mathrm{dL}$ ) and anemia with the need for increased doses of ESA. Four weeks after finishing therapy, she still has normal hepatic function with AST: 58 U/L; ALT: $71 \mathrm{U} / \mathrm{L}$; ALP: $147 \mathrm{U} / \mathrm{L}$; G-GT: $34 \mathrm{U} / \mathrm{L}$; however, she showed a viral relapse with RNA HCV $1.2 \times 10^{5} \mathrm{U} / \mathrm{L}$.

In our unit, HCV serology is performed using a third-generation, enzyme-linked imunoassay. All patients received their renal allografts from $\mathrm{HCV}$ negative donors.

\section{DISCUSSION}

The development of chronic hepatic disease and cirrhosis is more frequent in the renal transplant population who displayed chronic $\mathrm{HCV}$ infection. ${ }^{3,4} \mathrm{FCH}$ is a rare entity in 
renal transplantation; it appears to be associated with $\mathrm{HCV}$ with an incidence between $1.5 \%$ and $5 \% .9,10$

Among our patients, only the first case was known to be $\mathrm{HCV}$ positive; other two patients did not show anti-HCV antibodies. Unfortunately, the search for RNA HCV was not performed on these patients before transplantation, so it is impossible to determine whether they were in a window period or whether it was an old infection.

The altered hepatic function occurred between the first and third month after transplantation with a histological diagnosis only performed in the second and third month, which represented the time of peak hepatic dysfunction (Table 1). In the third patient, we performed only one biopsy. It was not sufficiently characteristic of FCH to achieve the diagnosis; the first biopsies of the first two patients were interpreted as cholestatic lesions from a probable toxic etiology. This was the reason why there was a change in maintenance therapy to sirolimus with suspension or dose reduction of FK. MMF was also terminated in all patients, and the dose of CT increased.

Once the diagnosis of FCH was established, there is little doubt about initiating therapy with PEG IFN $\alpha-2 b$ and ribavirin. However, it is important to note that adverse effects of interferon therapy on allograft survival are so well established that this treatment is reserved for patients with $\mathrm{FCH}$ where hepatic failure and death are usual complications. ${ }^{7,9,10}$ Renal allograft rejection is an usual complication of interferon therapy that complicates $9 \%$ to $100 \%$ of cases ${ }^{11}$ with the greatest scores associated with an early start of therapy. It seems that this treatment is associated with induction of cell surface expression of HLA alloantigens as well as increased antibody production by $\mathrm{B}$ cells and intracellular cytokine gene expression.

The observed viral load and viral genotypes forecasted a favorable response to therapy. The first two patients showed complete viral responses with a negative viral load and normalization of hepatic function tests. It is also important to note that both subjects maintained stable renal function with no need for the introduction of ESA therapy (Table 2).

The third patient had an impressive initial response to therapy; however, the renal dysfunction was aggravated with consequent anemia requiring discontinuation of therapy. These results are, however, difficult to interpret, since at the start of therapy she already had important renal dysfunction, which she maintains after discontinuing therapy.

Table 1. Peak Hepatic Dysfunction and HCV Genotype

\begin{tabular}{lccccc}
\hline & $\begin{array}{c}\text { Peak } \\
\text { Dysfunction } \\
(\mathrm{mo})\end{array}$ & $\begin{array}{c}\text { AST } \\
(\mathrm{U} / \mathrm{L}) / \mathrm{ALT} \\
(\mathrm{U} / \mathrm{L})\end{array}$ & $\begin{array}{c}\text { GGT } \\
(\mathrm{U} / \mathrm{L}) / \mathrm{ALP} \\
(\mathrm{U} / \mathrm{L})\end{array}$ & $\begin{array}{c}\text { Bilirubin } \\
(\mathrm{mg} / \mathrm{dL})\end{array}$ & $\begin{array}{c}\text { HCV } \\
\text { Genotype }\end{array}$ \\
\hline Case 1 & 3 & $168 / 122$ & $101 / 144$ & 20 & 2 \\
Case 2 & 2 & $750 / 1116$ & $1126 / 280$ & 6.4 & $3 \mathrm{a}$ \\
Case 3 & 5 & $462 / 373$ & $1901 / 569$ & 1.5 & $3 \mathrm{a}$
\end{tabular}

HCV, hepatitis C Virus; AST, aspartate aminotransferase; GGT, gammaglutamyltransferase; ALP, alanine aminotransferase.
Table 2. Evolution of the Renal Allograft Function in Time

\begin{tabular}{ccccc}
\hline \multicolumn{5}{c}{ Scr/MDRD } \\
$\begin{array}{c}\text { Renal } \\
\text { Function }\end{array}$ & Baseline & $\begin{array}{c}3 \text { mo of } \\
\text { Treatment }\end{array}$ & $\begin{array}{c}6 \text { mo of } \\
\text { Treatment }\end{array}$ & $\begin{array}{c}12 \text { mo of } \\
\text { Treatment }\end{array}$ \\
\hline Case 1 & $1.2 / 62$ & $1.3 / 57$ & $1.1 / 69$ & $1.3 / 57$ \\
Case 2 & $1.2 / 67$ & $1.1 / 74$ & $1.1 / 74$ & NA \\
Case 3 & $3.4 / 14$ & $4 / 12$ & $4.5 / 10$ & NA \\
\hline
\end{tabular}

Scr, serum creatinine (mg/dL); MDRD, Modification of Diet in Renal Disease study equation $\left(\mathrm{mL} / \mathrm{min} / 1.73 \mathrm{~m}^{3}\right)$; NA, not available.

Only the first patient experienced rejection episodes, which occurred 1 month after finishing therapy. The acute humoral rejection responded to immunoglobulin therapy. Finally, it is important to note that even the patients with viral relapses maintained stable hepatic function. Since FCH is usually associated with a grim prognosis, it seems reasonable to begin treatment to control hepatic damage that results from unchecked viral replication in the early posttransplant period during which the induction immunosuppressive protocols are initiated.

In conclusion, even if treatment of HCV infection after renal transplantation is not recommended due to the high risk of rejection, it should be performed when liver failure is imminent. ${ }^{5,7,12}$ We showed that treatment is possible with preservation of both renal and hepatic function in contrast to other series that report allograft loss, liver failure, and death in all patients. ${ }^{9,10}$

Among HCV-negative patients routine PCR detection of $\mathrm{HCV}$ should be introduced as a standard of care during the pretransplant period.

\section{REFERENCES}

1. Portuguese Society of Nephrology Registry, 2009, www. spnefro.pt

2. Pereira BJ, Natov SN, Bouthot BA, et al: Effects of hepatitis $\mathrm{C}$ infection and renal transplantation on survival in end-stage renal disease. The New England Organ Bank Hepatitis C Study Group, Kidney Int 53:1374, 1998

3. Batty DSJ, Swanson SJ, Kirk AD, et al: Hepatitis C virus seropositivity at the time of renal transplantation in the United States: Associated factors and patient survival. Am J Transplant 1:179, 2001

4. Espinosa M, Martin-Malo A, Alvarez de Lara MA, et al: Risk of death and liver cirrhosis in anti-HCV-positive long-term haemodialysis patients. Nephrol Dial Transplant 16:1669, 2001

5. Perico N, Cattaneo D, Bikbov B, et al: Hepatitis C infection and chronic renal diseases. Clin J Am Soc Nephrol 4:207, 2009

6. Fabrizi F, Lunghi G, Dixit V, et al: Meta-analysis: anti-viral therapy of hepatitis $C$ virus-related liver disease in renal transplant patients. Aliment Pharmacol Ther 24:1413, 2006

7. Norah A, Adey D: The kidney transplant recipient with hepatitis $\mathrm{C}$ infection: pre- and posttransplantation treatment. Clin J Am Soc Nephrol 2:563, 2007

8. Davies SE, Portmann BC, O'Grady JG, et al: Hepatic histological findings after transplantation for chronic hepatitis $\mathrm{B}$ virus infection, including a unique pattern of fibrosing cholestatic hepatitis. Hepatology 13:150, 1991 
9. Delladetsima J, Boletis J, Makris F, et al: Fibrosing cholestatic hepatitis in renal transplant recipients with hepatitis $C$ virus infection. Liver Transpl Surg 5:294, 1999

10. Bustillo E, Ibarrola C, Colina F, et al: Fibrosing cholestatic in hepatitis $\mathrm{C}$ virus-infected renal transplant recipients $\mathrm{J}$ Am Soc Nephrol 9:1109, 1998
11. Wéclawiack H, Kamar N, Meherenberger M, et al: Alphainterferon therapy for chronic hepatitis C may induce acute allograft rejection in kidney transplant patients with failed allografts. Nephrol Dial Transplant 23:1043, 2008

12. Viral hepatitis guidelines in hemodialysis and transplantation. Am J Transplant 4:72-82, 2004 